\title{
Reaction-ion-exchange Techniques Recovery of Valuable Components from Mineral and Technogenic Raw Materials and Production of the Dispersed Substances
}

\author{
Svetlana V. Saikova ${ }^{a *}$, \\ Gennady L. Pashkov ${ }^{b}$ and Marina V. Panteleeva ${ }^{b}$ \\ ${ }^{a}$ Siberian Federal University \\ 79 Svobodny, Krasnoyarsk, 660041, Russia \\ ${ }^{b}$ Institute of Chemistry and Chemical Technology of SB RAS \\ 50-24 Akademgorodok, Krasnoyarsk, 660036, Russia
}

Received 30.03.2015, received in revised form 09.04.2015, accepted 20.05.2015

Two different techniques of integrated ion exchange technology processes were researched. The first is recovery of metals from mineral raw materials, intermediate substances and waste products by cation exchange resins in H-form. The second is synthesis of dispersed materials utilizing anion exchange resins in $\mathrm{OH}$-, $\mathrm{CO}_{3^{-}}, \mathrm{C}_{2} \mathrm{O}_{4}$-forms. The constants of dissolution (leaching) and precipitation using ion exchange resin were determined. These techniques advantages before traditional leaching and precipitation methods are discussed. Application of methods is illustrated by cases of metal separation from its oxides, hydroxides, sulfides, silicates and synthesis different dispersed materials: cobalt and nickel hydroxides, oxalates, base carbonates and others. Mechanism of these processes and different factors influence on the processes are discussed.

Keywords: ion-exchange techniques, cation-exchanger, anion-exchanger, non-ferrous metals, oxides, hydroxides, oxalates.

(C) Siberian Federal University. All rights reserved

* Corresponding author E-mail address: ssai@mail.ru 


\title{
Реакционно-ионообменные методы извлечения \\ ценных компонентов из минерального \\ и техногенного сырья
}

и получения дисперсных продуктов

\author{
С.В. Сайкова ${ }^{a}$, \\ Г.Л. Пашков \\ ${ }^{a}$ Сибирский федеральный университет \\ Россия, 660041, Красноярск, пр. Свободный, 79 \\ ${ }^{6}$ Институт химии и химической технологии СО РАН \\ Россия, 660036, Красноярск, Академгородок, 50-24
}

\begin{abstract}
Рассматриваются два совмещенных реакционно-ионообменных процесса, в которых применяются органические иониты: катионообменное выщелачивание ионов металлов из минерального и техногенного сырья с использованием катионита в водородной форме и анионообменного осаждения ионов металлов в виде малорастворимых соединений с применением анионита в гидроксидной и солевых формах. Возможности методов иллюстрируются примерами разделения металлов, исходя из их оксидов, гидроксидов, сульфидов, силикатов, а также синтеза гидроксидов, карбонатов, оксалатов никеля, кобальта и других металлов.
\end{abstract}

Ключевые слова: ионообменные проиессы, катионит, анионит, ияетные металлы, оксиды, гидроксиды, оксалаты.

\section{Введение}

Ионообменные методы давно и эффективно применяются в промышленной водоподготовке, при очистке электролитов и сточных вод, при извлечении урана, золота и других металлов, в отдельных областях технологии неорганических и органических веществ. Основное преимущество ионного обмена заключается в способности ионообменного материала накапливать значительное количество извлекаемого компонента даже в случае ультранизкой его концентрации в растворе. При этом ионообменные процессы обладают достаточно высокой избирательной способностью и обеспечивают необходимую степень разделения. Особенно ярко проявляются достоинства ионного обмена в совмещенных реакционно-массообменных процессах, в которых химические превращения сопровождаются извлечением продукта из реакционной зоны. Успешную реализацию такого технологического подхода представляет сорбция из пульп (сорбционное выщелачивание). В этом случае непосредственно в ходе выщелачивания или по окончании процесса в систему вводится сорбент (ионит) для удаления накапливающихся продуктов из зоны реакции, что не только обеспечивает выделение целевого компонента, но и приводит к увеличению степени его извлечения за счет сдвига равновесия и подавления побочных взаимодействий. Нагруженный сорбент легко отделяется от сбросной пульпы, что позволяет ликвидировать стадию фильтрации пульп. Кроме того, применение ионита приводит к увеличению выхода продуктов, повышению селективности, обеспечению высокой движущей силы, снижению энерго- и материальных затрат, упрощению технологических схем. Однако при сорбционном выщелачивании реагент, вводимый в систему одновременно с сорбентом, рас-

$$
-483-
$$


ходуется по мере осуществления процесса, поэтому необходимо использование его высоких концентраций или постоянное добавление. К тому же в результате ионного обмена в растворе генерируются противоионы функциональных групп ионита. Все это приводит к увеличению ионной силы раствора, что отрицательно сказывается на полноте и избирательности сорбции.

Отмеченных недостатков лишён совмещенный реакционно-ионообменный процесс катионообменного растворения (выщелачивания), в котором выщелачивающий реагент (кислота) не вводится в систему, а генерируется в ходе ионного обмена, поскольку используется катионит в водородной форме, т.е. один и тот же реагент - катионит - используется и для растворения (выщелачивания) материала, и для сорбции образовавшегося продукта. Принципиальное отличие катионообменного растворения от сорбционного выщелачивания заключается в том, что в данном случае осуществляется не только сорбция ионов металла, т.е. отвод их из зоны реакции, но и генерируется обратный диффузионный поток - приток эквивалентного количества реагента (ионов водорода) в зону реакции, что, очевидно, обеспечивает более быстрое и полное протекание процесса.

Катионообменное растворение имеет значительные перспективы при создании новых технологических схем гидрохимической переработки бедного окисленного, а также техногенного сырья - огарков, возгонов, пылей и шламов металлургического, химического и топливноэнергетического комплексов, содержащих металлы в форме оксидов, гидроксидов, карбонатов и силикатов.

Реакционно-ионообменные методы могут быть применены и в осадительных схемах очистки и переработки продуктивных растворов, сточных вод, а также при синтезе различных соединений: прекурсоров катализаторов, гидроксидных электродных материалов, сложных оксидов и др. Основным недостатком метода реагентного осаждения является необходимость длительной отмывки образующегося осадка, зачастую труднокоагулируемого и коллоидного, от избытка осадителя, что приводит к образованию большого количества подлежащих утилизации промывных вод. Кроме того, вследствие высокой ионной силы растворов и явления локального пересыщения при осаждении сложно добиться формирования однородных по структуре, составу и морфологии, а также близких по свойствам частиц. Анионообменное осаждение, напротив, позволяет получать соединения реакционной чистоты и осуществлять синтез при низкой ионной силе. Однако разработка способов и определение условий анионообменного синтеза различных материалов требует установления закономерностей и изучения механизма химических превращений, протекающих при осуществлении данного процесса.

Цель данной работы - установление основных закономерностей совмещенных процессов, включающих ионный обмен на органических ионитах, катионообменного растворения и анионообменного осаждения как эффективных способов извлечения цветных металлов из окисленного рудного и техногенного сырья и получения дисперсных материалов.

\section{Материалы и методики эксперимента}

В работе использовали сильнокислотный сульфокатионит КУ-2-8 с полистирольной матрицей (ГОСТ 20298-74) в Н-форме и сильноосновный полистирольный анионит АВ-17-8 (ГОСТ 20301-74), содержащий остатки четвертичных аммониевых оснований, в $\mathrm{OH}-, \mathrm{CO}_{3}$-, $\mathrm{C}_{2} \mathrm{O}_{4}$-формах. В качестве объектов катионообменного растворения выбраны оксиды, гидрок- 
сиды, силикаты металлов (табл. 2), которые являются компонентами многих исходных или техногенных материалов современного производства. Использовали товарные оксиды (квалификация «хч» и «чда») $\mathrm{CoO}$ (ГОСТ 18671-73), $\mathrm{Co}_{3} \mathrm{O}_{4}$ (ГОСТ 4467-79), $\mathrm{NiO}$ (ГОСТ 4331-38), ZnO (ГОСТ 10262-73), CdO (ГОСТ 11120-75), FeO (ГОСТ ТУ 6-09-1404-76), СuО (ГОСТ 1653979), а также модельные образцы: $\mathrm{Fe}_{2} \mathrm{O}_{3}$, полученный обжигом пирита при 800 드, гидроксиды цинка, никеля и продукты совместного осаждения следующих пар металлов: кобальт и никель, никель и цинк, кобальт и железо. Гидроксиды синтезировали действием раствором аммиака на 0,5 М растворы сульфатов соответствующих металлов или их смеси. После отмывки полученных продуктов и выделения из маточного раствора их высушивали при $100{ }^{\circ} \mathrm{C}$. Состав модельных образцов, установленный с помощью количественного химического анализа, соответствовал формулам $\mathrm{NiSO}_{4} \cdot 5 \mathrm{Ni}(\mathrm{OH})_{2}, \mathrm{CoSO}_{4} \cdot 2 \mathrm{Co}(\mathrm{OH})_{\mathrm{x}}(2<\mathrm{x}<3), \mathrm{ZnSO}_{4} \cdot 3 \mathrm{Zn}(\mathrm{OH})_{2}$ и $\mathrm{CuSO}_{4} \cdot 3 \mathrm{Cu}(\mathrm{OH})_{2}$.

РФА образцов проводили методом порошков (порошки помещали на монокристалл кремния) в интервале углов $0^{\circ}<2 \Theta<80^{\circ}$, время накопления импульсов -2 с (X'Pert PRO PIXcel фирмы PANalytical, CuK излучение). Идентификацию фаз осуществляли с помощью картотеки Powder Diffraction File JCPDSD-ICDD PDF.

Для исследования методом ИК-Фурье-спектроскопии (Vector 22 фирмы Bruker) образцы прессовали в виде дисков со спектрально чистым КВr. Навески вещества и матрицы были постоянными, каждый спектр получался в результате 100 сканирований в интервале 450-4000 см-1 с разрешением $2 \mathrm{~cm}^{-1}$.

Концентрацию металлов в растворе или суммарные ее значения в случае смеси катионов устанавливали с помощью комплексонометрического титрования, а также йодометрически или фотоколориметрически [1-3]. На основании полученных данных рассчитывали значения коэффициентов разделения $\mathrm{T}_{\mathrm{M}_{2}}^{\mathrm{M}_{1}}$ по формуле

$$
\mathrm{T}_{\mathrm{M}_{2}}^{\mathrm{M}_{1}}=\frac{\mathrm{n}_{\mathrm{M}_{1}}^{\mathrm{KaT}}}{\mathrm{n}_{\mathrm{M}_{1}}^{\mathrm{oc}}} \cdot \frac{\mathrm{n}_{\mathrm{M}_{2}}^{\mathrm{oc}}}{\mathrm{n}_{\mathrm{M}_{2}}^{\mathrm{KaT}}},
$$

где $n_{\mathrm{M}}^{\text {кат }}$ - количество металла, извлеченного в фазу катионита, $n_{\mathrm{M}}^{\text {ос }}-$ количество металла, оставшееся в осадке. Относительная ошибка не превышала 3 \%.

\section{Катионообменное растворение}

Движущей силой катионообменного растворения, протекающего, например, для растворения оксида (гидроксида) двухзарядного металла по уравнению

$$
2 \mathrm{R}-\mathrm{H}+\mathrm{MO}\left(\mathrm{M}(\mathrm{OH})_{2}\right)=\mathrm{R}_{2} \mathrm{M}+\mathrm{H}_{2} \mathrm{O},
$$

где RH - катионит в водородной форме, является не только связывание катиона фазой ионита, но и образование слабодиссоциирующего соединения (в данном случае воды) между противоионами катионита и анионной составляющей выщелачиваемой фазы. При этом обеспечивается значительная полнота протекания процесса.

Катионообменное растворение включает две сопряженные гетерогенные реакции, протекающие на границах раздела фаз твердое вещество - раствор и раствор - сорбент:

$$
-485-
$$


кислотное растворение твердой фазы

$$
\mathrm{MO}+\mathrm{H}_{2} \mathrm{O}=\left(\mathrm{M}(\mathrm{OH})_{2}\right)=\mathrm{M}^{2+}+2 \mathrm{OH}^{-}, \quad \Pi \mathrm{P}=\mathrm{a}_{\mathrm{M}^{2+}} \cdot \mathrm{a}_{\mathrm{OH}^{-}}^{2}
$$

и ионный обмен между образующимися ионами металла и катионитом

$$
\mathrm{M}^{2+}+2 \mathrm{R}-\mathrm{H}=2 \mathrm{H}^{+}+\mathrm{R}_{2} \mathrm{M}, \quad \mathrm{K}_{\text {обм. }}=\frac{\mathrm{a}_{\mathrm{H}^{+}}^{2} \cdot \mathrm{a}_{\mathrm{R}_{2} \mathrm{M}}}{\mathrm{a}_{\mathrm{R}-\mathrm{H}}^{2} \cdot \mathrm{a}_{\mathrm{M}^{2+}}},
$$

где $\mathrm{a}_{\mathrm{R}-\mathrm{H}}$ и $\mathrm{a}_{\mathrm{R}}{ }_{2} \mathrm{M}-$-активности функциональных групп ионита в водородной и металл-формах соответственно.

После суммирования (3) и (4) получаем уравнение (2), которое характеризуется следующей константой катионообменного растворения:

$$
\mathrm{K}_{\text {к.p. }}=\frac{\mathrm{a}_{\mathrm{R}_{2} \mathrm{M}}}{\mathrm{a}_{\mathrm{R}-\mathrm{H}}^{2}}=\frac{\Pi \mathrm{P} \cdot \mathrm{K}_{\text {обм. }}}{\mathrm{K}_{\mathrm{w}}^{2}} .
$$

Исследование влияния на катионообменное растворение оксидов цинка и меди природы функциональных групп катионита и макроструктуры полимерной матрицы (табл. 1) показало, что рК ионита является определяющим фактором: скорость процесса быстро снижается (практически до нуля) с увеличением рК функциональных групп, в то же время применение макропористого сорбента КУ-2-16П вместо гелевого КУ-2-8 в пределах ошибки эксперимента не сказывается на протекании процесса, что свидетельствует об отсутствии прямого взаимодействия между ионитом и металлсодержащей фазой. Действительно, гелевые иониты имеют малый размер пор (в основном 6-10 А̊ для КУ-2-8), что делает недоступным большую часть фиксированных групп даже для наноразмерных частиц. Таким образом, был выбран гелевый катионит КУ-2-8, который характеризуется хорошими кинетическими свойствами, значительным рабочим интервалом $\mathrm{pH}$ и широко используется в промышленности. С применением КУ-2-8 нашли значения эффективных констант катионообменного растворения оксидов и гидроксидов цинка и меди: $\mathrm{K}_{\text {к.p. }}\left(\mathrm{Zn}(\mathrm{OH})_{2}\right)=(2,9 \pm 0,1) \cdot 10^{13}, \mathrm{~K}_{\text {к.р. }}(\mathrm{ZnO})=(2,9 \pm 0,1) \cdot 10^{11}$, $\mathrm{K}_{\text {к.р. }}\left(\mathrm{Cu}(\mathrm{OH})_{2}\right)=(3,0 \pm 0,1) \cdot 10^{10}, \mathrm{~K}_{\text {к.p. }}(\mathrm{CuO})=(3,6 \pm 0,1) \cdot 10^{9}$, значения которых свидетельствуют о том, что процесс катионообменного растворения этих материалов практически необратим. Термодинамическая обусловленность процесса подтверждается найденными значениями изменения энтальпии и энтропии катионообменного растворения $\mathrm{ZnO}: \Delta \mathrm{H}^{0}=-56,1$ кДж/моль; $\Delta \mathrm{S}^{0}=32$ Дж/моль К.

Таблица 1. Влияние природы функциональных групп катионита на время растворения оксидов цинка и меди (II)

\begin{tabular}{|c|c|c|c|}
\hline \multirow{2}{*}{ Катионит } & \multirow{2}{*}{$\mathrm{pK}_{\text {функц.групп }}$} & \multicolumn{2}{|c|}{ Время полного растворения } \\
\cline { 3 - 4 } & 2 & $\mathrm{ZnO}$ & СuО \\
\hline КУ-2-8 & 2 & $1,3 \pm 0,2$ ч & $72 \pm 12$ ч \\
\hline КУ-2-16П & $3-4$ & $1,4 \pm 0,2$ ч & $72 \pm 12$ ч \\
\hline КРФ-5 & $4-6$ & $7,0 \pm 0,5$ сут & $60 \pm 2$ сут \\
\hline КБ-4 & $>5$ месяцев & $>5$ месяцев \\
\hline
\end{tabular}


Таблица 2. Результаты катионообменного растворения оксидов металлов

\begin{tabular}{|c|c|c|}
\hline Оксид & $\begin{array}{c}\text { Продолжительность } \\
\text { растворения, мин }\end{array}$ & $\begin{array}{c}\text { Молярная доля металла, } \\
\text { извлеченного в фазу катионита }\end{array}$ \\
\hline $\mathrm{CdO}$ & 5 & 1,00 \\
\hline $\mathrm{ZnO}$ & 9 & 1,00 \\
\hline $\mathrm{CoO}$ & 15 & 1,00 \\
\hline $\mathrm{CuO}$ & 60 & 0,85 \\
\hline $\mathrm{FeO}$ & 60 & 0,78 \\
\hline $\mathrm{Fe}_{2} \mathrm{O}_{3} ; \mathrm{Co}_{3} \mathrm{O}_{4} ; \mathrm{NiO}$ & 60 & 0,00 \\
\hline
\end{tabular}

Кроме достижения полноты извлечения ионов металлов при катионообменном растворении обеспечивается также избирательность процесса, которая обусловлена возможностью проведения его вдали от равновесия с использованием различия в кинетике растворения твердой фазы. Кинетические данные для катионообменного растворения оксидов цветных металлов приведены в табл. 2.

Наиболее быстро растворяются оксиды кадмия, цинка и кобальта (II), тогда как скорость катионообменного растворения оксида никеля (II), а также кобальта (II, III) и железа (III) практически близка к нулю. То есть в присутствии катионита растворяются в основном оксиды металлов в степени окисления +2 . Исключение составляет оксид никеля (II), который отличается от других оксидов значительно меньшей концентрацией носителей заряда. В [4] отмечается: чем больше концентрация носителей заряда, тем больше скорость кислотного растворения оксидов. Высокие скорости гидроксилирования поверхности оксидов цинка и кадмия обеспечивают быстрое катионообменное растворение этих материалов. Таким образом, в зависимости от свойств твёрдых фаз скорость их растворения значительно различается, что можно использовать для разделения металлов. Кроме того, как показали наши исследования, для различных материалов также неодинакова зависимость скорости их катионообменного растворения от режима термообработки и условий проведения процесса, т.е. $\mathrm{pH}$ раствора, температуры, соотношения фаз и др. Варьируя режим обработки твердой фазы и условия выщелачивания, можно добиваться селективного извлечения целевого компонента.

Для определения оптимальных условий разделения металлов при катионообменном выщелачивании использовали метод математического планирования и обработки результатов эксперимента. Получили уравнения регрессии, отражающие влияние различных факторов на скорость извлечения металлов из окисленных материалов [5-8]. Полученные значения коэффициентов разделения металлов, присутствующих в различных природных, техногенных и синтетических веществах, приведены в табл. 3 .

При разделении совместно осажденных гидроксидов Ni и Со величина коэффициента разделения ниже ожидаемого. По нашему мнению, это является следствием некоторых побочных взаимодействий: образования твердых растворов, окклюдирования, ингибирования кристаллизации. Для остальных пар достигнуты значительные коэффициенты разделения.

Катионообменное растворение протекает в мягких условиях, без использования экологически опасных реагентов, не вызывает коррозии оборудования. В частности, при использова-

$$
-487-
$$


Таблица 3. Значения коэффициентов селективности, достигаемые при сорбционном выщелачивании металлсодержащих продуктов

\begin{tabular}{|l|c|c|c|}
\hline \multicolumn{1}{|c|}{$\begin{array}{c}\text { Объект катионообменного } \\
\text { выщелачивания }\end{array}$} & $\begin{array}{c}\text { Температура } \\
\text { термообработки, }{ }^{\circ} \mathrm{C}\end{array}$ & $\begin{array}{c}\text { Ион металла, } \\
\text { изекаемый в фазу } \\
\text { катионита }\end{array}$ & $\begin{array}{c}\text { Коэффициент } \\
\text { разделения }\end{array}$ \\
\hline \multicolumn{3}{|c|}{ Механические смеси } \\
\hline $\mathrm{Cu}(\mathrm{OH})_{2}$ и $\mathrm{Zn}(\mathrm{OH})_{2}$ & 800 & $\mathrm{Zn}^{2+}$ & 13 \\
\hline $\mathrm{Ni}(\mathrm{OH})_{2}$ и $\mathrm{Zn}(\mathrm{OH})_{2}$ & 800 & $\mathrm{Zn}^{2+}$ & 18 \\
\hline $\mathrm{Ni}(\mathrm{OH})_{2}$ и Со $(\mathrm{OH})_{2}$ & 400 & $\mathrm{Ni}^{2+}$ & $\mathrm{Cu}^{2+}$ \\
\hline Смесь хризоколлы и гарниерита & - & $\mathrm{Ni}^{2+}$ & 2 \\
\hline \multicolumn{2}{|c|}{ Совместно осажденные гидроксиды } \\
\hline $\mathrm{Ni}-\mathrm{Co}$ & 400 & $\mathrm{Co}^{2+}$ & 439 \\
\hline $\mathrm{Co}-\mathrm{Fe}$ & 100 & $\mathrm{Zn}^{2+}$ & $>10^{5}$ \\
\hline $\mathrm{Zn}-\mathrm{Ni}$ & 800 & \\
\hline
\end{tabular}

нии катионитов выщелачивание кремнийсодержащих материалов не осложняется коллоидообразованием, однако его эффективность в значительной степени зависит от природы силиката и типа руды. Так, хризоколла $\left(\mathrm{Cu}, \mathrm{Al}_{2} \mathrm{H}_{2} \mathrm{Si}_{2} \mathrm{O}_{5}(\mathrm{OH})_{4} \cdot \mathrm{nH}_{2} \mathrm{O}\right.$, являющаяся продуктом химического выветривания медных руд, в отличие от гарниерита $(\mathrm{Ni}, \mathrm{Mg})_{6}\left[\mathrm{Si}_{4} \mathrm{O}_{10}\right](\mathrm{OH})_{8}$ активна в процессах катионообменного растворения.

Установленные закономерности сорбционного растворения были использованы при разработке способа извлечения скандия из техногенного сырья - золошлаковых отходов (ЗШО) сжигания углей Бородинского месторождения $[9,10]$. Известные методы извлечения скандия из зол бурого угля, например, спеканием со щелочью или содой с последующим выщелачиванием, обеспечивают невысокий процент извлечения скандия (не более 50 \%). В случае же прямого солянокислого вскрытия может быть достигнуто 75-85\%-ное выщелачивание скандия, но возникают проблемы со значительным расходом кислоты, коррозией оборудования и необходимостью очистки скандийсодержащих растворов от примесных элементов. Для исследования катионообменного извлечения скандия использовали летучие золы, полученные при температуре сжигания угля $800{ }^{\circ} \mathrm{C}$, поскольку выше этой температуры начинаются процессы остекловывания и зола теряет свою реакционоспособность. С помощью рентгенофазового анализа установили, что главным компонентом золы является кремнезем. Кроме того, она содержит сульфат и карбонат кальция и небольшое количество алюмосиликатов кальция. Полученные результаты показали, что сорбционное выщелачивание способствует отделению скандия от мешающих ионов, в частности железа. Так, в оптимальных условиях молярное отношение $\mathrm{Fe} /$ Sc c 2000 в золе снижается до 14 в ионите, а степень извлечения скандия достигает 65 \%. Проведение второй стадии выщелачивания золы повышает степень извлечения скандия до $85 \%$. Таким образом, остаточная массовая доля скандия в золе составляет $5 \cdot 10^{-4} \%$.

В процессе сорбционного выщелачивания ЗШО в катионит переходят также ионы кальция. Их отделение достигается на стадии элюирования катионита: при использовании раствора, содержащего 0,9 $\mathrm{M} \mathrm{Na}_{2} \mathrm{SO}_{4}$ и 0,1 $\mathrm{M} \mathrm{H}_{2} \mathrm{SO}_{4}, 98$ \% кальция, извлекается из ионита за одну стадию в виде твёрдой фазы $\mathrm{CaSO}_{4}$, что снижает минерализацию стоков, являющуюся основной пробле- 
мой ионообменной технологии. При этом 70 \% скандия остаётся в фазе ионита и вымывается на второй стадии элюирования катионита $1 \mathrm{M} \mathrm{H}_{2} \mathrm{SO}_{4}$.

\section{Анионообменное осаждение}

Процесс анионообменного осаждения подобно катионообменному растворению включает две сопряженные гетерогенные реакции, протекающие на двух границах раздела фаз в системе твёрдое вещество - раствор низкомолекулярного электролита (водная фаза) - раствор сшитого полиэлектролита (ионит): анионный обмен между сорбентом и раствором и осаждение малорастворимого соединения металла из раствора. Осаждение, например, сульфата двухзарядного металла с помощью анионита в А-форме $\left(\mathrm{A}=\mathrm{OH}^{-}, \mathrm{HCO}_{3}^{-}, 1 / 2 \mathrm{CO}_{3}^{2-}, 1 / 2 \mathrm{C}_{2} \mathrm{O}_{4}{ }^{2-}\right.$ и др.) описывает суммарное уравнение (6)

$$
\mathrm{MSO}_{4}+2 \mathrm{RA}=\mathrm{R}_{2} \mathrm{SO}_{4}+\mathrm{MA}_{2} \downarrow
$$

где $\mathrm{RA}$ и $\mathrm{R}_{2} \mathrm{SO}_{4}$ - анионит в исходной А-форме и $\mathrm{SO}_{4}$ - форме (после обмена).

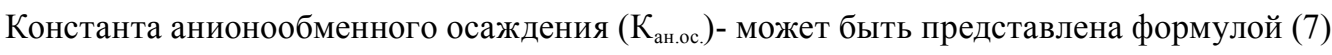

$$
\mathrm{K}_{\text {aн.oc. }}=\frac{\mathrm{a}_{\mathrm{R}_{2} \mathrm{SO}_{4}} \cdot \mathrm{a}_{\mathrm{A}^{-}}^{2}}{\mathrm{a}_{\mathrm{RA}}^{2} \cdot \mathrm{a}_{\mathrm{M}^{2+}} \cdot \mathrm{a}_{\mathrm{SO}_{4}^{2-}} \cdot \mathrm{a}_{\mathrm{A}^{-}}^{2}}=\frac{\mathrm{K}_{\text {обм. }}}{\Pi_{\mathrm{MA}_{2}}},
$$

где $\mathrm{a}_{\mathrm{R}_{2} \mathrm{SO}_{4}}$ и $\mathrm{a}_{\mathrm{RA}}-$ активности $\mathrm{SO}_{4}^{2-}$ и $\mathrm{A}^{-}-$ионов в фазе ионита, $\mathrm{a}_{\mathrm{SO}_{4}^{2-}}$ и $\mathrm{a}_{\mathrm{M}^{2+}}$ - активности ионов $\mathrm{SO}_{4}{ }^{2-}$ и $\mathrm{M}^{2+}$ в растворе; ПР - произведение растворимости малорастворимого продукта $\mathrm{MA}_{2}$; $\mathrm{K}_{\text {обм. }}$ - константа анионного обмена из раствора.

Поскольку катионы исходного вещества (прекурсора) связываются в слабодиссоциирующее или малорастворимое соединение, а анионы переходят в фазу сорбента, то равновесие оказывается практически полностью сдвинутым в сторону продуктов. Действительно, определенное нами на основании справочных и экспериментальных данных значение константы анионообменного осаждения, например гидроксида кобальта, равно 4,5·10 $0^{16}$. Как показали расчеты, в целом анионообменный синтез термодинамически обусловлен для соединений, имеющих величину ПР $<10^{-5}$, причем для сравнительно полного осаждения металла достаточно одностадийного взаимодействия раствора его соли и анионита.

Было показано, что выход продукта в значительной степени зависит от природы функциональных групп анионита и структуры полимерной матрицы. При использовании пористых анионитов (Lewatit MP 600WS, AB-17-8П, ЭДЭ-10П) значительная доля металла переходит в фазу сорбента вследствие его осаждения в виде гидроксида или основной соли в порах анионита. Установлено также, что слабоосновные аниониты в ОН-форме с $\mathrm{pK}>3$ практически не осаждают ионы кобальта или никеля из раствора, а сорбируют их вследствие координационного взаимодействия с функциональными группами анионита. В результате проведенного исследования определено, что наиболее эффективен для анионообменного осаждения сильноосновный гелевый анионит АВ-17-8, который к тому же является коммерчески доступным.

В ходе исследования установлено влияние различных факторов на выход продуктов синтеза и определены оптимальные условия получения различных фаз: гидроксидов кобальта и

$$
-489-
$$


Таблица 4. Состав продуктов анионообменного синтеза, полученных в оптимизированных условиях синтеза

\begin{tabular}{|c|c|c|c|c|c|}
\hline \multirow{2}{*}{ Исходная соль } & \multicolumn{3}{|c|}{ Содержание, мас. \% } & \multirow{2}{*}{ Предполагаемая формула } \\
\cline { 2 - 4 } & $\mathrm{M}^{2+}$ & $\mathrm{CO}_{3}^{2-}$ & $\mathrm{Co}^{3+}$ & $\mathrm{NO}_{3}{ }^{-2}$ & \\
\hline $\mathrm{Ni}\left(\mathrm{NO}_{3}\right)_{2}$ & 60,0 & 8,3 & - & отс. & $\mathrm{Ni}(\mathrm{OH})_{1,74}\left(\mathrm{CO}_{3}\right)_{0,13}$ \\
\hline $\mathrm{Co}\left(\mathrm{NO}_{3}\right)_{2}$ & 62,0 & 6,6 & отс. & отс. & $\mathrm{Co}(\mathrm{OH})_{1,80}\left(\mathrm{CO}_{3}\right)_{0,10}$ \\
\hline $\mathrm{Co}\left(\mathrm{NO}_{3}\right)_{2}$ & 56,5 & 25,2 & отс. & отс. & $\mathrm{Co}(\mathrm{OH})_{1,12}\left(\mathrm{CO}_{3}\right)_{0,44}$ \\
\hline $\mathrm{Co}\left(\mathrm{NO}_{3}\right)_{2}$ & 32,2 & - & отс. & отс. & $\mathrm{CoC}_{2} \mathrm{O}_{4} \cdot 2 \mathrm{H}_{2} \mathrm{O}$ \\
\hline $\mathrm{Ni}\left(\mathrm{NO}_{3}\right)_{2}$ & 32,2 & - & - & отс. & $\mathrm{NiC}_{2} \mathrm{O}_{4} \cdot 2 \mathrm{H}_{2} \mathrm{O}$ \\
\hline
\end{tabular}

никеля, основного карбоната кобальта, оксалатов кобальта и никеля с использованием анионита в соответствующей форме.

Было определено, что анионообменное осаждение из-за отсутствия непосредственного взаимодействия между исходными веществами, а также выведения из системы анионов, изначально присутствующих в растворе, приводит к формированию продуктов, гораздо более чистых, чем при реагентном осаждении. Так, изучение полученных соединений комплексом химических и физических методов показало, что они в отличие от осадков, получаемых щелочным или аммиачным осаждением, свободны от катионов натрия и кобальта (III) и не содержат анионов исходной соли (табл. 4).

Анионообменный синтез протекает при постоянном значении $\mathrm{pH}$, которое, однако, можно варьировать в определенных пределах, меняя тип анионита или природу функциональной группы, а также количество сорбента в системе. Таким образом, можно проводить синтез при заданных условиях и получать необходимую модификацию продукта. В ходе исследования определены условия синтеза тетрагональной модификации оксида циркония (IV), применяющейся при получении катализаторов [11]. В ходе анионообменного осаждения гидроксидов кобальта и никеля, протекающего при $\mathrm{pH}=6-7$, формируется метастабильная $\alpha$-модификация, трудно достижимая методом реагентного осаждения. Структура $\alpha$-модификации отличается значительной разупорядоченностью слоев, состоящей из октаэдров $\mathrm{CoO}_{6}$, при этом в межслоевом пространстве расположены анионы и молекулы воды. Она имеет лучшие электрохимические характеристики по сравнению с наиболее часто применяющейся $\beta$-модификацией, поэтому может быть использована при создании электродных материалов для источников тока, а также как многообещающий прекурсор при синтезе наноразмерных материалов на основе никеля и кобальта $[12,13]$.

Анализ полученных результатов позволил выделить следующие стадии анионообменного синтеза малорастворимых соединений: анионный обмен, осаждение продукта, протекающее, скорее всего, на поверхности зерен ионита, и отслаивание осадка при достижении определенной толщины. Если отслаивание тормозится, то лимитирующей стадией становится взаимодиффузия анионов прекурсора и противоионов анионита через слой поверхностного осадка. Процесс осложняется побочными взаимодействиями (молекулярная сорбция, комплексообразование в растворе и фазе сорбента), степень протекания которых в значительной степени зависит от условий осуществления синтеза. 
Таблица 5. Влияние природы противоиона анионита на осаждение кобальта из раствора $\mathrm{Co}\left(\mathrm{NO}_{3}\right)_{2}$

\begin{tabular}{|c|c|c|c|}
\hline Природа противоиона & Время процесса, ч & Выход продукта, \% & $\begin{array}{c}\text { Доля кобальта } \\
\text { в фазе ионита, \% }\end{array}$ \\
\hline $\mathrm{OH}^{-}$ & 1 & 40 & 5 \\
\hline $\mathrm{CO}_{3}{ }^{-2}$ & 60 & 65 & 20 \\
\hline $\mathrm{HCO}_{3}^{-}$ & 3 & 30 & 25 \\
\hline $\mathrm{C}_{2} \mathrm{O}_{4}{ }^{--}$ & 1 & 25 & 57 \\
\hline
\end{tabular}

Таблица 6. Влияние природы аниона исходной соли на результаты анионообменного синтеза

\begin{tabular}{|c|c|c|c|}
\hline \multirow{2}{*}{ Исходная соль } & \multicolumn{3}{|c|}{ Молярная доля металла в фазах } \\
\hline & раствора & осадка & анионита \\
\hline \multicolumn{4}{|c|}{ Синтез гидроксида никеля } \\
\hline $\mathrm{Ni}\left(\mathrm{NO}_{3}\right)_{2}$ & $0,10 \pm 0,03$ & $0,72 \pm 0,07$ & $0,05 \pm 0,01$ \\
\hline $\mathrm{NiSO}_{4}$ & $0,08 \pm 0,03$ & $0,70 \pm 0,07$ & $0,07 \pm 0,02$ \\
\hline $\mathrm{NiCl}_{2}$ & $0,08 \pm 0,03$ & $0,73 \pm 0,07$ & $0,04 \pm 0,01$ \\
\hline \multicolumn{4}{|c|}{ Синтез гидроксида кобальта } \\
\hline $\mathrm{Co}\left(\mathrm{NO}_{3}\right)_{2}$ & $0,41 \pm 0,05$ & $0,25 \pm 0,05$ & $0,02 \pm 0,02$ \\
\hline $\mathrm{CoCl}_{2}$ & $0,33 \pm 0,04$ & $0,33 \pm 0,05$ & $0,02 \pm 0,02$ \\
\hline $\mathrm{CoSO}_{4}$ & $0,26 \pm 0,04$ & $0,39 \pm 0,06$ & $0,02 \pm 0,02$ \\
\hline \multicolumn{4}{|c|}{ Синтез основного карбоната кобальта } \\
\hline $\mathrm{Co}\left(\mathrm{NO}_{3}\right)_{2}$ & $0,05 \pm 0,01$ & $0,48 \pm 0,08$ & $0,35 \pm 0,06$ \\
\hline $\mathrm{CoCl}_{2}$ & $0,06 \pm 0,02$ & $0,26 \pm 0,07$ & $0,55 \pm 0,08$ \\
\hline $\mathrm{CoSO}_{4}$ & $0,09 \pm 0,03$ & $0,16 \pm 0,06$ & $0,67 \pm 0,09$ \\
\hline
\end{tabular}

Сравнительное исследование процесса анионообменного осаждения кобальта и никеля анионитом в ОН-, $\mathrm{CO}_{3}-, \mathrm{HCO}_{3}-$ и $\mathrm{C}_{2} \mathrm{O}_{4}$-формах показало, что природа противоиона в значительной степени влияет как на скорость процесса синтеза, так и на выход продукта (табл. 5).

Вероятно, это влияние определяется не столько различием в ПР образующихся продуктов, сколько свойствами поверхностного осадка. Видимо, плотность поверхностного осадка и/или его адгезионные свойства максимальны при использовании анионита в $\mathrm{CO}_{3}$-форме, что приводит к незначительной скорости процесса.

Влияние природы аниона исходной соли различно для разных продуктов синтеза (табл. 6). Так, оно практически отсутствует при получении гидроксида никеля и является определяющим фактором при синтезе основного карбоната кобальта.

По нашему мнению, оно определяется не столько положением аниона в лиотропном ряду, сколько его участием в протекании побочных процессов, в частности молекулярной сорбции электролита фазой анионита, которая максимальна для сульфата кобальта. К тому же природа аниона исходной соли в значительной степени влияет на свойства поверхностного осадка. Так, в случае анионообменного синтеза основного карбоната кобальта установили, что наиболее

$$
-491-
$$




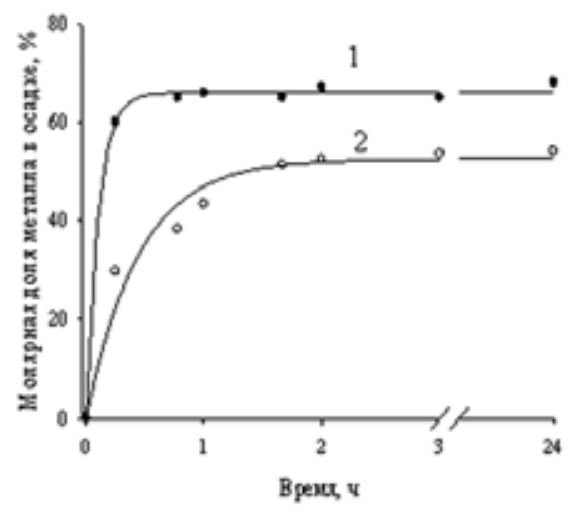

a

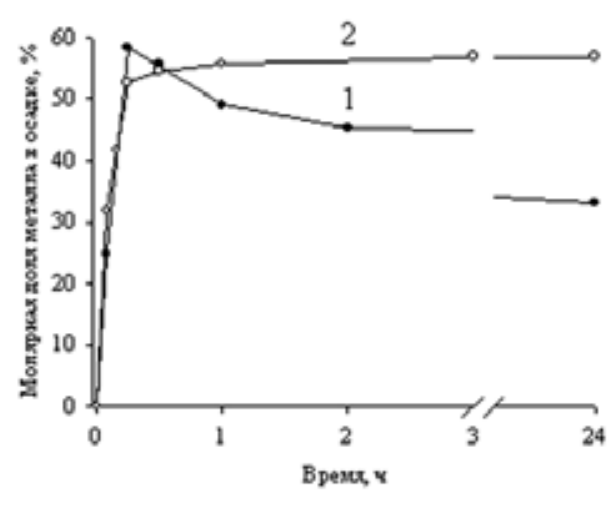

6

Рис. 1. Молярная доля металла в осадках гидроксидов (а) и оксалатов (б) никеля (1) и кобальта (2) в зависимости от времени при осаждении из растворов $\mathrm{MSO}_{4}$

плотный поверхностный осадок образуется из сульфатного раствора, а наименее плотным является осадок из $\mathrm{Co}\left(\mathrm{NO}_{3}\right)_{2}$.

На рис. 1 приведены зависимости выхода гидроксидов и оксалатов никеля и кобальта от времени при проведении процесса из сульфатных растворов.

Различия в количестве образующегося осадка отчасти можно объяснить разницей в их

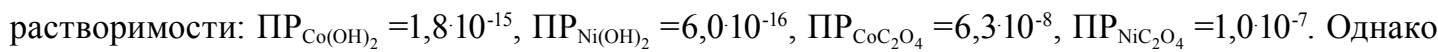
при анионообменном осаждении оксалатов выход продукта в значительной степени зависит от степени протекания побочного процесса - комплексообразования. Образующиеся частицы $\mathrm{MC}_{2} \mathrm{O}_{4}(\mathrm{M}=\mathrm{Ni}, \mathrm{Co})$ реагируют с $\mathrm{C}_{2} \mathrm{O}_{4}{ }^{2-}-$ анионами раствора или функциональными группами анионита с образованием анионного комплекса (8)

$$
\mathrm{C}_{2} \mathrm{O}_{4}{ }^{2-}+\mathrm{MC}_{2} \mathrm{O}_{4}=\left[\mathrm{M}\left(\mathrm{C}_{2} \mathrm{O}_{4}\right)_{2}\right]^{2-}
$$

что в определенных условиях приводит к частичному растворению осадка оксалата металла, образовавшегося на начальной стадии синтеза, поэтому необходимо контролируемое анионообменное осаждение.

При анионообменном синтезе, проводимом из смеси солей, образуются прекурсоры, обладающие высокой активностью, поэтому образование сложных оксидов (ферритов, алюминатов и др.) протекает при более низкой температуре, к тому же контроль за осуществлением осаждения позволяет получать прекурсоры состава, близкого к стехиометрическому, что способствует образованию однофазного материала.

Проводили также анионообменное соосаждение пар катионов $\left(\mathrm{Al}^{3+}\right.$ и $\mathrm{Co}^{2+}, \mathrm{Al}^{3+}$ и $\mathrm{Ni}^{2+}$, $\mathrm{Al}^{3+}$ и $\mathrm{Fe}^{3+}, \mathrm{Y}^{3+}$ и $\mathrm{Fe}^{3+}$ ) из растворов, содержащих смесь соответствующих солей. Установление оптимальных условий и методики осуществления процесса позволило получать наноразмерные прекурсоры, не содержащие примесных атомов, близкого к стехиометрическому состава. Это не только способствует образованию однофазного материала, но и вследствие высокой химической активности прекурсоров их взаимодействие, приводящее к образованию сложных оксидов (алюминатов кобальта и никеля, алюмоиттриевого и железо-иттриевого 
гранатов), протекает при более низкой температуре (на 300-400 을 ниже, чем указано в литературе) [14-18].

В результате проведенных исследований установлено, что ионообменные методы имеют ряд преимуществ перед традиционными гидрометаллургическими технологиями и могут быть использованы для разделения металлов, для выделения их из руд и отходов производства, а также для получения чистых веществ и высокоактивных прекурсоров синтеза наноразмерных материалов и сложных оксидных фаз.

\section{Список литературы}

[1] Шапиро С.А. Аналитическая химия. М.: Высшая школа, 1973. 344 с.

[2] Приибил Р. Комплексоны в химическом анализе. М.: Химия, 1960. 242 с.

[3] Муравьев А.Г. Руководство по определению показателей качества воды полевыми методами. СПб.: Крисмас, 1999. 245 с.

[4] Segall R., Smart R.S.C., Turner P.S. // J. Chemistry in Australia. 1982. Vol. 49. № 6. P. 241-245.

[5] Николаева Р.Б., Пашков Г.Л., Сайкова С.В., Ефимова М.Ю. // ЖПХ. 1993. Т. 66. № 2. С. 458-461.

[6] Пашков Г.Л., Николаева Р.Б., Сайкова С.В., Драгун О.П. // ЖПХ. 1994. Т. 67. № 9. C. 1441-1444.

[7] Пашков Г.Л., Николаева Р.Б., Сайкова С.В., Голубева Т. В. // ЖПХ. 1994. Т.67. № 9. C. $1566-1568$.

[8] Николаева Р.Б., Пашков Г.Л., Сайкова С.В. // ЖПХ. 1994. Т. 67. № 8. С. 1386-1388.

[9] Пашков Г.Л., Николаева Р.Б., Сайкова С.В. и др. // Химическая технология. 2000. № 10. C. 25-29.

[10] Пашков Г.Л., Сайкова С.В., Кузьмин В.И. и др. // Журнал СФУ. Техника и технологии. 2012. (5). № 5. 520-530.

[11] Пашков Г.Л., Сайкова С.В., Пантелеева М.В. Пат. 2400429 РФ (2010) / Б.И. 2010. № 27.

[12] Сайкова С.В., Пантелеева М.В., Николаева Р.Б., Пашков Г.Л. // ЖПХ. 2002. Т. 75. № 11. C. $1823-1825$.

[13] Сайкова С.В., Пантелеева М.В., Николаева Р.Б. // Вестник КГУ. Естественные науки. 2003. № 2. C. 110-114.

[14] Пашков Г.Л., Сайкова С.В., Пантелеева М.В., Линок Е.В., Самойло А.С., Бондаренко Г.Н. // Стекло и керамика. 2013. Т.70. № 6. С. 28-31.

[15] Пашков Г.Л., Сайкова С.В., Пантелеева М.В. и др. // Известия вузов. Химия и химическая технология. 2013. Т. 56. №. 8. С. 77-81.

[16] Пашков Г.Л., Сайкова С.В., Пантелеева М.В. Пат. 2424190 РФ (2013) / Б. И. 2013. № 14.

[17] Пашков Г.Л., Сайкова С.В., Пантелеева М.В., Линок Е.В. Пат. 2484025 РФ (2013) / Б. И. 2013. № 16.

[18] Пашков Г.Л., Сайкова С.В., Пантелеева М.В., Линок Е.В. Пат. 2484025 РФ (2014) / Б. И. 2014. № 8 . 